\title{
Development of an Evaluating Method for Carbon Emissions of Manufacturing Process Plans
}

\author{
Yanhong Wang, ${ }^{1}$ Hua Zhang, ${ }^{2}$ Zhiqing Zhang,, and Jing Wang ${ }^{1}$ \\ ${ }^{1}$ School of Management, Wuhan University of Science \& Technology, Wuhan 430081, China \\ ${ }^{2}$ School of Machinery and Automation, Wuhan University of Science \& Technology, Wuhan 430081, China \\ Correspondence should be addressed to Yanhong Wang; wyhwust@126.com
}

Received 26 August 2014; Revised 20 October 2014; Accepted 6 November 2014

Academic Editor: Tinggui Chen

Copyright (c) 2015 Yanhong Wang et al. This is an open access article distributed under the Creative Commons Attribution License, which permits unrestricted use, distribution, and reproduction in any medium, provided the original work is properly cited.

\begin{abstract}
Carbon intensity reduction and energy utilization enhancement in manufacturing industry are becoming a timely topic. In a manufacturing system, the process planning is the combination of all production factors which influences the entail carbon emissions during manufacturing. In order to meet the current low carbon manufacturing requirements, a carbon emission evaluation method for the manufacturing process planning is highly desirable to be developed. This work presents a method to evaluate the carbon emissions of a process plan by aggregating the unit process to form a combined model for evaluating carbon emissions. The evaluating results can be used to decrease the resource and energy consumption and pinpoint detailed breakdown of the influences between manufacturing process plan and carbon emissions. Finally, the carbon emission analysis method is applied to a process plan of an axis to examine its feasibility and validity.
\end{abstract}

\section{Introduction}

In recent years, there have been great concerns on energy consumption and carbon emission in manufacturing processes in response to the global trends towards sustainable manufacturing [1]. Resource and energy are consumed during each stage of manufacturing processes. The utilizing of fossil fuels results in a significant increase in carbon dioxide $\left(\mathrm{CO}_{2}\right)$, which is one of the foremost greenhouse gases (GHG) [2]. Due to the continuous rise of demand and consumption of manufactured goods, in 2010, China's emissions reached around $25 \%$ of world's $\mathrm{CO}_{2}$ emissions and China's manufacturing sector accounted for about $60 \%$ of the total consumption. [3]. Therefore, reducing resource usage and carbon emissions generation of manufacturing processes, especially improving their efficiency, has become an emerging topic in environmentally benign manufacturing.

Carbon emission assessment is the initial step to monitor the resource and energy consumptions and identify opportunities for improvement. Under the quantitative calculation perspective, carbon emissions are often calculated using the ISO accredited method life cycle assessment (LCA). The method was developed using life cycle inventory to analyze the cumulative environment impacts of a process or product through all the stages of its life [4]. As a key technology of green design, LCA has a very active role for the analysis of the impact on the environment in the life cycle of products. However, LCA method is limited due to the lack of accurate data related to energy across a product life cycle (in particular during the manufacturing phase) [5]. Moreover, LCA is heavily influenced by the subjective factors and does not quantitatively analyze these factors.

Considering that carbon emissions are directly related to energy production, some eminent works modeling and analyzing energy consumption of manufacturing processes have been done by many researchers. Jeswiet and Kara [6] proposed a method that connects the electrical energy used in manufacturing directly to the carbon emissions that are created in using the electrical energy. Duflou et al. [7] pointed out that an effectiveness approach might change the process chain entirely and cause a dramatically smaller amount of the energy consumption and carbon emission generation. Weinert et al. [8] presented an EnergyBlocks methodology for 
accurate energy consumption prediction, integrating energyefficiency criteria with evaluation and decision processes during production system planning and scheduling. Choi and Xirouchakis [9] focused on a production planning problem in a highly automated manufacturing system considering multiple process plans with different energy requirements. Fang et al. [10] proposed a new mathematical programming model of the flow shop scheduling in manufacturing for reduction of power consumption and carbon footprint. Laurent et al. [11] discussed the appropriateness of carbon footprint as an overall indicator of the environmental performance for manufacturing industry. Herrmann and Thiede [12] presented an integrated concept to foster energy efficiency in manufacturing companies on different layers to take into account the interdependencies of all technical processes (production and technical building services).

Additionally, some research studies provide an insight into the further decomposition of the energy consumption to support carbon emission assessment. Rahimifard et al. [13] investigated the specific product energy to support energy efficient manufacturing through modeling the detailed breakdown of energy required to produce a single product. Li et al. [14] developed a carbon emission analysis model integrating the new evaluation indicator (carbon efficiency) to improve the electronics manufacturing process. Trappey et al. [15] established an economic input-output life cycle assessment approach to evaluate the carbon emissions of new products and identify problematic carbon emissions within the supply chain. Li et al. [16] proposed an analytical method of quantifying carbon emissions of a CNC (Computer Numerical Control) based machining system and analyzed the breakdown of the processes that contribute to the overall carbon emissions of a CNC-based machining system.

While the literature seems abundant, few efforts are received to provide the quantitative evaluation method of carbon emission for a process plan. Since manufacturing process plans serve as a pivotal link between design and manufacturing, carbon emissions reduction can be achieved through advances in manufacturing, especially with more efficient process planning [17]. For instance, Fysikopoulos et al. [18] developed analytical models to assess the energy requirements on various laser manufacturing processes for proposing processing strategies. However, the methodology for calculation of the embodied carbon emissions arising from manufacturing processes has not yet been satisfactorily developed. As a result, process chains design and planning strongly influencing the carbon emissions of manufacturing should not be ignored [19]. Thus, the research on manufacturing process plans to decrease the carbon emissions would be an important step forward towards low carbon manufacturing.

In this paper, an evaluation method is presented to quantitatively analyze the carbon emission of manufacturing process plans. This method aggregates the unit process to form a combined model and then quantifies the amount of carbon emissions from individual processes. The model form permits identification of opportunities for reducing carbon emissions at the unit process level and driving the whole process towards low carbon emission based on an

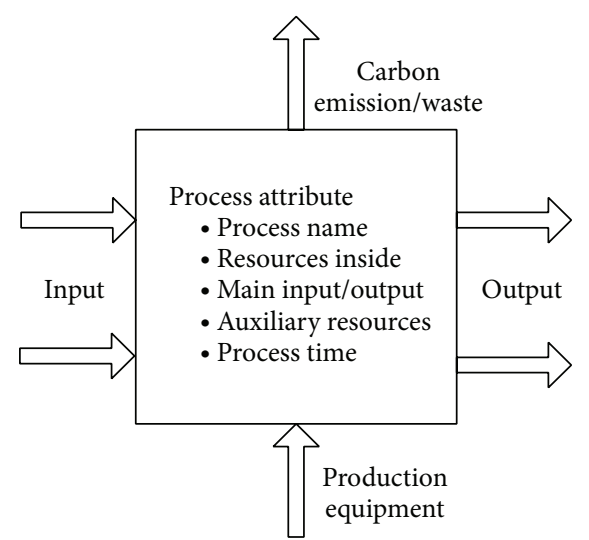

Figure 1: Basic process model.

examination of the aggregated manufacturing process level mode. An illustrative example in a manufacturing process plan of an axis production is presented to demonstrate how to apply the carbon emissions calculation method.

\section{Carbon Emission Model of Manufacturing Process Plans}

Due to the different processes employed, even a small change in product process design, the impact on the environment will be very different. In order to assess the carbon emission of manufacturing process plans, the processing method in how the product is produced should be fully investigated.

In a manufacturing system, a process plan is the combination of diverse production processes and operations, and the ultimate aim is to turn the input resources into consumer products. Each process has its own attribute. The basic elements [20] of process include the input/output resource and energy, resource and energy flow inside, intermediate products and auxiliary resource and energy, emissions, waste, production equipment, and the manufacturing environment in which the process is carried out (see Figure 1).

For the convenience of research, the unit manufacturing process is introduced in this paper. Generally, unit manufacturing processes are classified into nonshaping processes and shaping processes. Nonshaping processes mean the processes used for modifying the properties of material, for example, surface treatment. Shaping processes refer to the processes used for modifying the part geometry, including casting, forming and shaping, and other nontraditional machining. Through the input and output data analysis of each unit process, the amount of carbon emissions can be accumulatively calculated and provide a measure to examine how carbons are influenced by the process plans.

In product manufacturing, material and energy flows go through operations and processes and are transformed into products (or semiproducts) as well as carbon emissions [13]. A carbon emission analysis framework is proposed to account for the causes of carbon emissions, as shown in Figure 2.

Carbon emissions occur accompanied with resource and energy consumption. According to the different types of the 


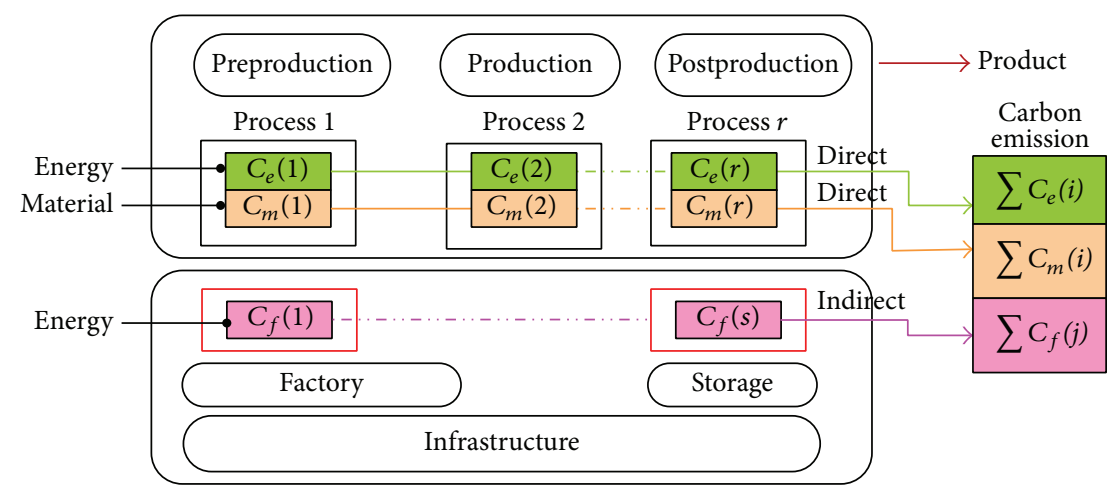

FIGURE 2: Carbon emission analysis framework for a product manufacturing.

input resources and energy type, carbon emissions include direct emission and indirect emission. Direct emission mainly refers to the emissions generated by the manufacturing processes, including consumption of operational energy and material during the manufacturing process; indirect carbon emissions arising during other nonoperational phases in product manufacturing mainly refer to carbon emissions generated by power consumption, including hydraulic device, transmission device, and other electric devices.

The total carbon emission of a manufacturing process plan, $C_{T}$, can be calculated as the sum of the carbon emissions generated from various process and can be expressed as follows:

$$
C_{T}=\sum_{i=1}^{r}\left(C_{e}(i)+C_{m}(i)\right)+\sum_{j=1}^{s} C_{f}(j),
$$

where $C_{e}(i)$ is the directed energy related carbon emission of the $i$ th unit process in the process plan, $C_{m}(i)$ is the material-related carbon emission of the $i$ th unit process in the process plan, and $C_{f}(j)$ is the indirect energy-related carbon emission of $j$ th zone in manufacturing plant.

Given that the whole manufacturing process plan is viewed as process-based architecture for the manufacturing operation, in fact individual processes can be a good way to the further decomposition of the energy consumption to support carbon emission assessment.

\subsection{Calculation of Directed Energy-Related Carbon Emissions} of a Unit Process. The carbon emissions generated from direct energy consumption are highly affected by the specific processing parameters and states (e.g., equipment standby, material cutting, and idle running of equipment). The energy consumption for a unit process can be formulated following the approach adapted from [21]

$$
\begin{aligned}
E_{\text {total }}(i) & =E_{\text {tip }}(i)+E_{\text {idle }}(i)+E_{\text {basic }}(i) \\
& =\int_{0}^{T_{\text {tip }}} P_{i} d_{t}+P_{\text {idle }} \cdot T_{\text {idle }}+P_{\text {basic }} \cdot T_{\text {basic }}
\end{aligned}
$$

where, for the $i$ th unit process, $E_{\text {total }}(i)$ is the total energy consumed, $E_{\text {tip }}(i)$ is the energy associated with the productive part of the operation (e.g., energy during cutting of the material) which is a function of operating parameters, $E_{\text {basic }}(i)$ is the "basic" energy consumed by fundamental activities of the manufacturing equipment (e.g., NC controller, lighting, and way lube system), $E_{\text {idle }}(i)$ is the "idle" energy consumed (e.g., cutting fluid pump and rapid traverse of the machine) when there is no active processing, $T_{\text {tip }}$ is total processing time, $P_{\text {idle }}$ is the total "idle" power, $T_{\text {idle }}$ is the time in a state of "idle," $P_{\text {basic }}$ is defined as the "basic" power, and $T_{\text {basic }}$ refers to the time in a state of "basic." $P_{i}$ is the total power during the process of cutting material, composed of standby power $P_{u}$, cutting power $P_{c}$, and additional load loss power $P_{a}$ (the certain power loss generated by the load of workpieces), Hu et al. [22]. Thus,

$$
P_{i}=P_{u}+P_{c}+P_{a} .
$$

The energy from each unit process can then be converted to a carbon emission using the following equation:

$$
C_{e}(i)=E_{\text {total }}(i) * \alpha_{\text {elec }},
$$

where $C_{e}(i)$ is the carbon emissions of the energy consumed in the $i$ th unit process and $\alpha_{\text {elec }}$ is the conversion factor for electricity to carbon emissions. $\alpha_{\text {elec }}$ varies considerably because of the differences in generating resources among utility service areas and seasonal variations. The data used in this paper is adapted from the study conducted by Department of National Development and Reform Commission in China [23]. In particular, we take the average of these grids' emission factors in Table 1 as the $\alpha_{\text {elec }}$.

2.2. Calculation of Material-Related Carbon Emissions of a Unit Process. The material-related carbon emissions of a unit process are determined by the material consumptions (mainly containing fossil energy consumption, hydraulic oil consumption and cutting fluid consumption, etc.) in the unit process. The carbon emissions due to $w$ different types of material consumption during a unit process can be calculated using the following equation:

$$
C_{m}(i)=\sum_{k=1}^{w} m_{k}(i) \alpha_{k}(i),
$$

where $C_{m}(i)$ is the total carbon emissions of the material flows for the $i$ th unit process in the process plan, $m_{k}(i)$ is the mass 
TABLE 1: Electricity carbon emission factors.

\begin{tabular}{lc}
\hline Name of power grid & $\begin{array}{c}\mathrm{CEF}_{\text {elec }} \\
\left(\mathrm{kg} \mathrm{CO}_{2} / \mathrm{kwh}\right)\end{array}$ \\
\hline North China Power Grid & 0.7802 \\
Northeast China Power Grid & 0.7242 \\
East China Power Grid & 0.6826 \\
Middle China Power Grid & 0.5802 \\
Northeast China Power Grid & 0.6433 \\
South Power Grid & 0.5722 \\
The National Average & 0.6747 \\
\hline
\end{tabular}

for the $k$ th type of material used in the $i$ th unit process, and $\alpha_{k}(i)$ is the conversion factor for the $k$ th type of material to carbon emission in the $i$ th process. The conversion factors for each of the $w$ types of materials can be obtained either through an LCA software package or through published reports or papers.

\subsection{Calculation of Indirect Energy-Related Carbon Emissions} of a Unit Process. The carbon emissions caused by auxiliary resource and energy consumptions are mainly including the electrical energy consumption of ancillary equipment in manufacturing plant, for example, lighting, heating, and ventilation. Usually, the manufacturing plant can be refined into a series of zones with similar indirect energy-related resource and energy consumptions [21]. In this approach, the carbon emissions attributed to a part in zone $j$ (i.e., $C_{f}(j)$ ) can be calculated by multiplying the total indirect energy consumed of zone $j$ with the conversion factor for energy to carbon emissions (i.e., $\alpha_{\text {elec }}$ ), as expressed in (5):

$$
C_{f}(j)=E_{f}(j) \cdot \alpha_{\text {elec }}
$$

Consequently, the indirect energy-related carbon emissions of total zone $s$ can be represented as

$$
\sum_{j=1}^{s} C_{f}(j)=\sum_{j=1}^{s} E_{f}(j) \cdot \alpha_{\text {elec }} .
$$

Empirical analysis is another way to quantify the indirect energy-related carbon emissions.

\subsection{Carbon Emission Evaluation Based Optimization Strategy.}

Once quantitative values are determined for each unit process and breakdown of carbon emission, a range of improvement opportunities can be identified to monitor the resource and energy consumptions during the entire process planning. Each improvement opportunity has been linked to a positive effect on at least one previously identified carbon emission. At times, the improvement opportunities should come at a trade-off on both economic and environmental goals. Therefore, implementing an improvement opportunity is beneficial in reducing carbon emission and meeting other sustainability goals. A carbon emission evaluation based optimization framework is as shown in Figure 3.

Following the quantitative calculation of carbon emission, the possibilities for reducing the resource consumption and carbon emission are assessed. Through synthesizing consideration of manufacturing equipment selection, operational efficiency, and product specification, a series of actions could be taken as follows to prevent the negativity influence according to a specific carbon emission source.

(i) Process technology selection: in the actual manufacturing process, one part can be generally manufactured by several feasible process technologies, but every process exhibits significant differences in resource and energy consumption. Modification or implementation of best available process technology can greatly improve the control of total carbon emission in a process plan.

(ii) Machine tool selection: machine tools have become increasingly complex and automated; these changes resulted in different energy requirements and limited access to resources. In the manufacturing of products, machine tools are the major carbon emission sources; therefore, applying an appropriate machine tool for production has a significant contribution to reduce the total power consumption.

(iii) Optimal resource consumption: the highest contributor to the carbon emissions is the raw material consumption. Besides the carbon emission is directly generated by the production of the raw materials and other resources; in addition, the utilizing of these resources also formed a huge amount of carbon emissions indirectly because of the material deduction processes and the generation of scrap. The resource consumption for each process unit needs to be carefully investigated and controlled.

Nowadays, manufacturing process plans undergo the continuous modification and optimization to meet the current LCM strategy. Through quantitative analysis of the carbon emission impact among the process technology, equipment, and operational parameter, a manufacturing process plan with the least carbon emission can be selected.

\section{Case Study}

This section gives a case study to verify and analyze the validity and applicability of the proposed approach described in Section 2. A process plan was revised from the manufacturing of an axis by Wuhan Valve, Inc.; for this axis, the existing process plan was obtained from a manufacturing engineer that oversees the production of the axis. The process plan generally contains the following steps: turning, milling, drilling, and grinding, as shown in Figure 4. It is to be noted that some of the processes have multiple operations associated with them. The intermediate steps of inspection are not shown due to the relatively low impact they have on the carbon emissions.

Once the process plan is available, the direct resource and energy flows (raw material and energy, auxiliary material and energy) need be analyzed and quantified. For the quantitative analysis of the carbon emissions of the process plan, the 


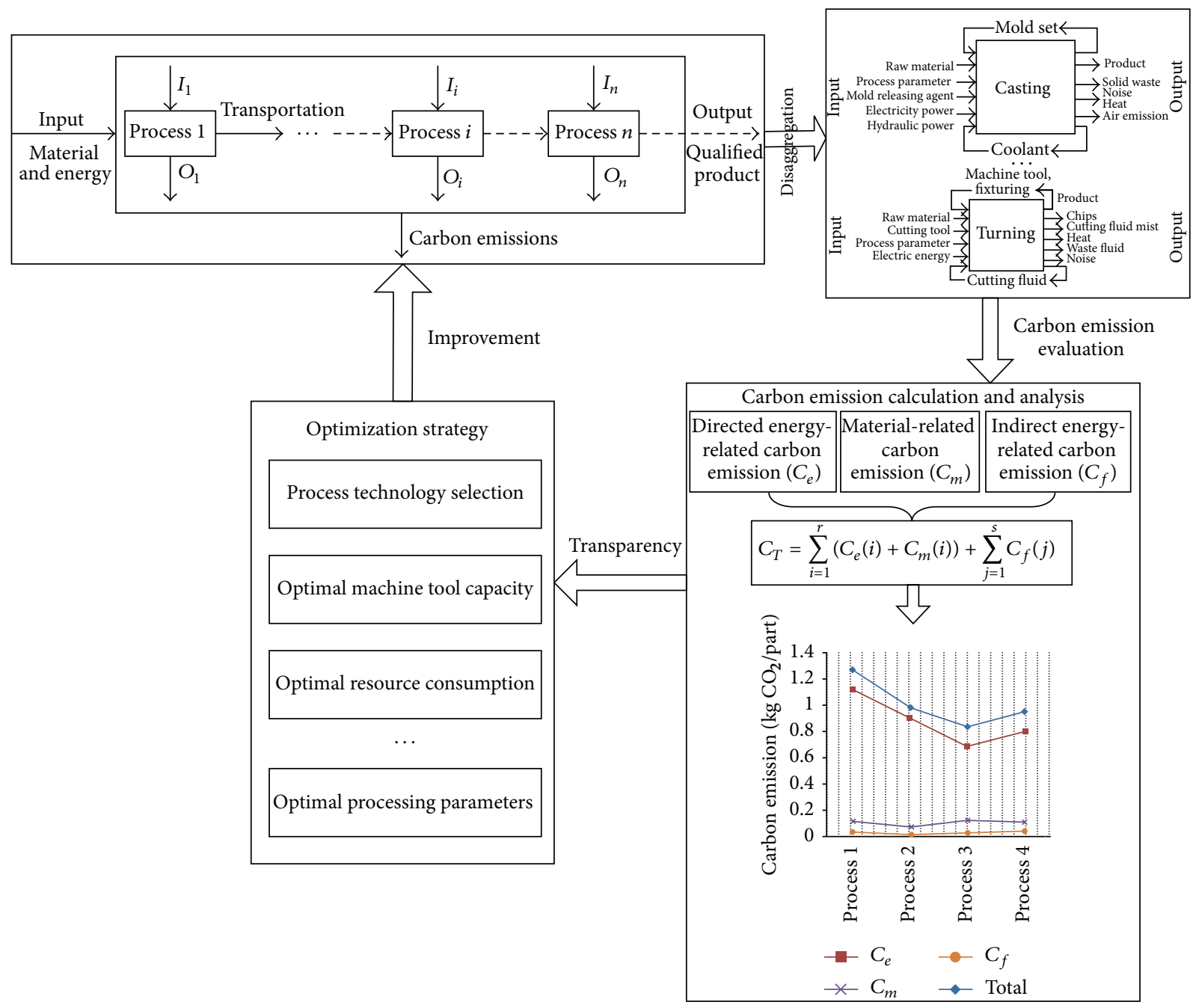

FIGURE 3: Carbon emission evaluation based optimization framework.

energy and material consumption data of each unit process need be collected.

The tip, idle, and basic energy of each unit process and the energy consumption of certain process in given zone were derived from one of three sources: a power study using a Fluke 435 Power Logger, a true RMS (Root Mean Square) multimeter, or product specifications. The values for the variables in (2), as well as the source of the data, are listed in Table 2 for each of the unit processes.

The material inputs and outputs of a unit process could include cutting fluid, cutting tool, and chips. Cutting tools are considered to be insignificant due to the little consumption for a part manufacturing; thus carbon emissions of cutting tools consumption were emitted in this case. For the quantity of the material inputs/outputs in each unit process, measurement and estimation based on discussions with machine operators were used. The data of conversion factors for each type of materials can be obtained either through an LCA software package, or through published reports or papers.
The values used for the variables in (3) are listed in Table 3 for each unit process.

Using these values, the total carbon emission for each of the processes in the process plan can be calculated using (1). The carbon emission related to energy consumption, material flows, and their sums for each unit process in the process plan are listed in Table 4.

The calculated value of carbon emissions for the manufacture of the axis is shown in Figure 5.

The breakdown results can be applied to quantify the carbon emission sources for the manufacture of the axis. The highest contributor to the carbon emissions is rough turning process (1.26). This is followed by fine turning process (0.9855) and milling process (0.947), respectively; and grinding process contributes the least (0.838). In addition, the carbon emissions of the direct energy consumed (3.494) are the largest across all operations. Based on this analysis, the most effective way to reduce carbon emission is to improve rough turning operation and decrease the direct energy 

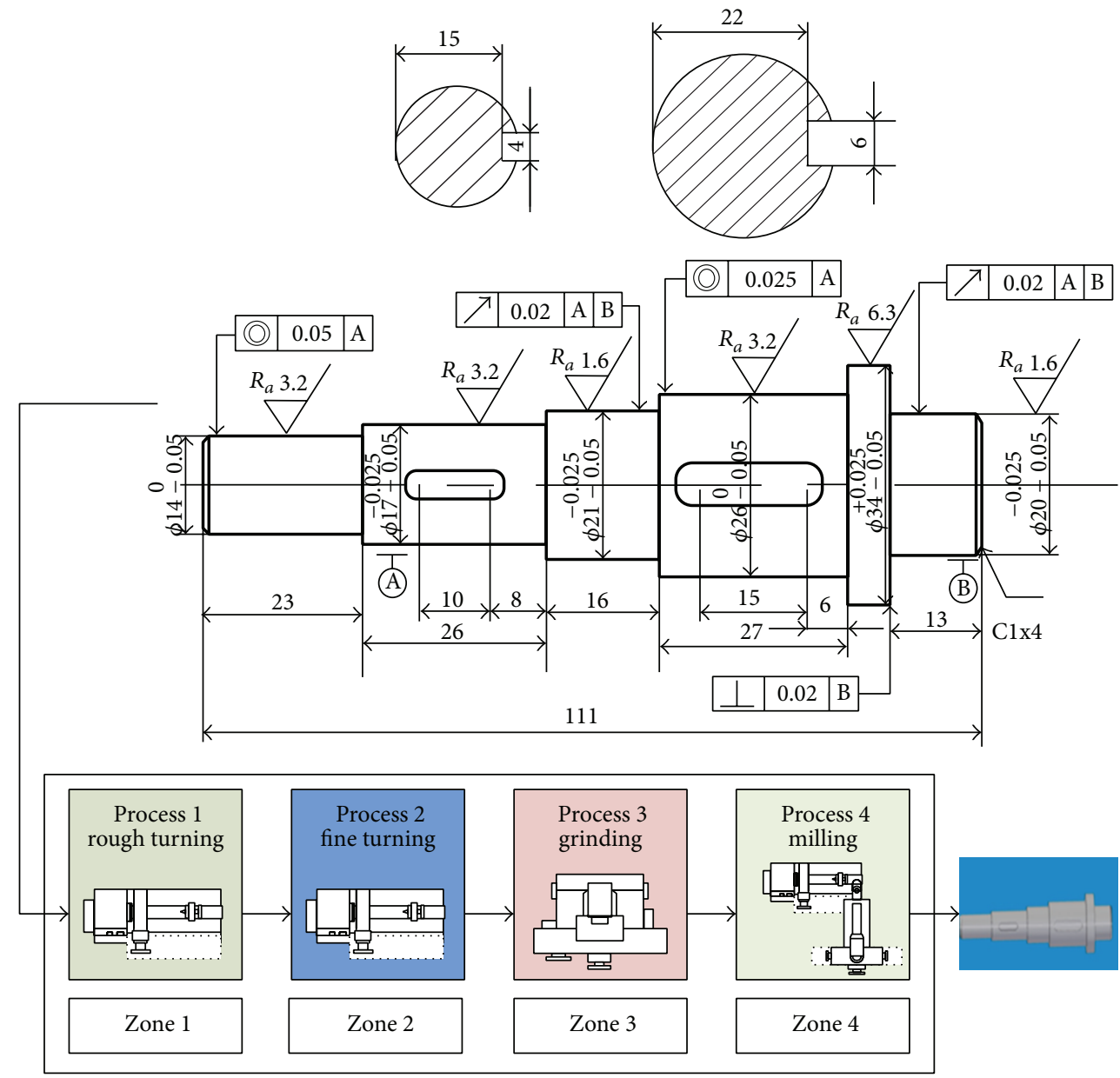

FIGURE 4: The existing process plan for the axis.

TABLE 2: Variables for the calculation of the energy-related carbon emissions.

\begin{tabular}{|c|c|c|c|c|}
\hline Process & $\begin{array}{l}\text { Rough } \\
\text { turning }\end{array}$ & $\begin{array}{c}\text { Fine } \\
\text { turning }\end{array}$ & Grinding & Milling \\
\hline $\begin{array}{l}\text { Process label } \\
\text { Machine }\end{array}$ & $\begin{array}{c}P_{1} \\
\text { CA6136 }\end{array}$ & $\begin{array}{c}P_{2} \\
\text { CA6136 }\end{array}$ & $\begin{array}{c}P_{3} \\
\text { MD1420 }\end{array}$ & $\begin{array}{c}P_{4} \\
\times 5032\end{array}$ \\
\hline $\begin{array}{l}\text { Process time } \\
(\mathrm{min})\end{array}$ & 26 & 6.5 & 4 & 3.2 \\
\hline $\begin{array}{l}E_{\text {tip }}(i) \\
\text { (kwh/part) }\end{array}$ & 0.65 & 0.45 & 0.32 & 0.38 \\
\hline $\begin{array}{l}E_{\text {idle }}(i) \\
\text { (kwh/part) }\end{array}$ & 0.48 & 0.36 & 0.25 & 0.24 \\
\hline $\begin{array}{l}E_{\text {basic }}(i) \\
(\text { kwh/part })\end{array}$ & 0.52 & 0.52 & 0.45 & 0.56 \\
\hline $\begin{array}{l}E_{\text {total }}(i) \\
(\mathrm{kwh} / \text { part })\end{array}$ & 1.65 & 1.33 & 1.02 & 1.18 \\
\hline $\begin{array}{l}E_{\text {zone }}(i) \\
\text { (kwh/part) }\end{array}$ & 0.05 & 0.02 & 0.04 & 0.06 \\
\hline $\begin{array}{l}a_{\text {energy }} \\
\left(\mathrm{kg} \mathrm{CO}_{2} / \mathrm{kwh}\right)\end{array}$ & 0.6747 & 0.6747 & 0.6747 & 0.6747 \\
\hline $\begin{array}{l}\mathrm{C}_{e}(i) \\
\left(\mathrm{kg} \mathrm{CO}_{2} / \text { part }\right)\end{array}$ & 1.113 & 0.897 & 0.688 & 0.796 \\
\hline $\begin{array}{l}\mathrm{C}_{f}(i) \\
\left(\mathrm{kg} \mathrm{CO}_{2} / \text { part }\right)\end{array}$ & 0.034 & 0.0135 & 0.027 & 0.041 \\
\hline
\end{tabular}

TABLE 3: Variables for the calculation of the material-related carbon emissions.

\begin{tabular}{lcccc}
\hline Process label & $P_{1}$ & $P_{2}$ & $P_{3}$ & $P_{4}$ \\
\hline $\begin{array}{l}m_{1} \\
\text { (waste steel scrap, }\end{array}$ & 0.18 & 0.12 & 0.09 & 0.15 \\
$\mathrm{~kg} /$ part) & & & & \\
$\begin{array}{l}m_{2} \\
\text { (water-based cutting } \\
\text { fluid, kg/part) }\end{array}$ & 0.24 & 0.16 & 0.45 & 0.28 \\
$\begin{array}{l}a_{1} \\
(\mathrm{~kg} \mathrm{CO} / \mathrm{kg})\end{array}$ & 0.361 & 0.361 & 0.361 & 0.361 \\
$\begin{array}{l}a_{2} \\
(\mathrm{~kg} \mathrm{CO} / \mathrm{kg})\end{array}$ & 0.2 & 0.2 & 0.2 & 0.2 \\
$\begin{array}{l}C_{m}(i) \\
(\mathrm{kg} \mathrm{CO} / \text { part })\end{array}$ & 0.113 & 0.075 & 0.123 & 0.11 \\
\hline
\end{tabular}

consumption of equipment. Clearly, the evaluating model not only can be used to make decision for manufacturing process plan with least carbon emissions but also provides opportunities for improvement, through further research of the relationship between operation factors of a process plan and the carbon emissions. 
TABLE 4: The total carbon emissions of each unit process.

\begin{tabular}{|c|c|c|c|c|c|}
\hline Process label & $P_{1}$ & $P_{2}$ & $P_{3}$ & $P_{4}$ & Total $\left(C_{j}\right)$ \\
\hline $\begin{array}{l}\mathrm{C}_{e}(i) \\
\left(\mathrm{kg} \mathrm{CO}_{2} / \text { part }\right)\end{array}$ & 1.113 & 0.897 & 0.688 & 0.796 & 3.494 \\
\hline $\begin{array}{l}\mathrm{C}_{m}(i) \\
\left(\mathrm{kg} \mathrm{CO}_{2} / \text { part }\right)\end{array}$ & 0.113 & 0.075 & 0.123 & 0.11 & 0.421 \\
\hline $\begin{array}{l}\mathrm{C}_{f}(i) \\
\left(\mathrm{kg} \mathrm{CO}_{2} / \text { part }\right)\end{array}$ & 0.034 & 0.0135 & 0.027 & 0.041 & 0.1155 \\
\hline Total $\left(P_{i}\right)$ & 1.26 & 0.9855 & 0.838 & 0.947 & 4.0305 \\
\hline
\end{tabular}

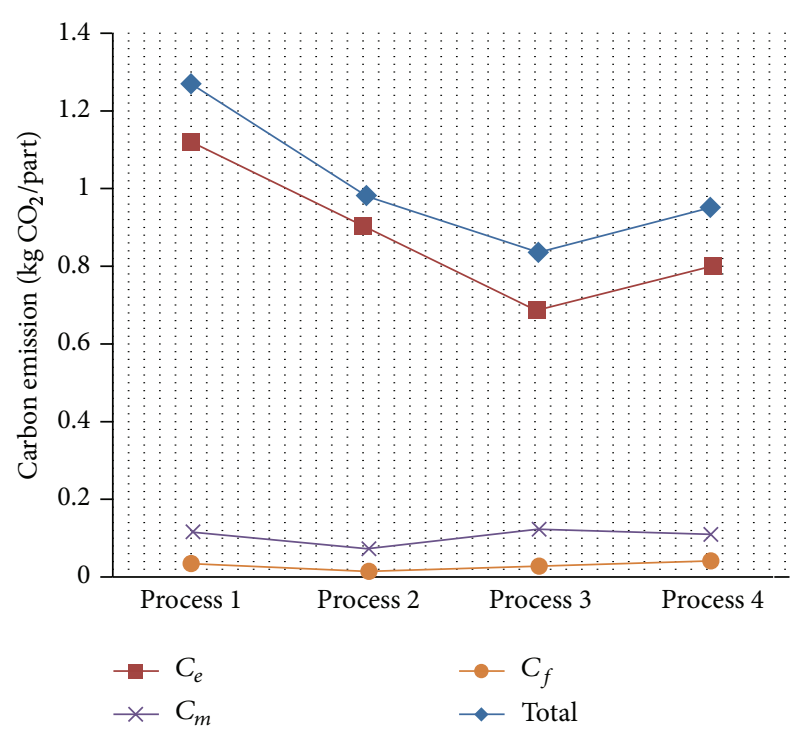

FIGURE 5: Breakdown of carbon emissions for the manufacture of the axis.

\section{Conclusions}

Evaluation is increasingly being regarded as the key step to meet the LCM strategy for further technological innovation and implementation in industry. Instead of considering carbon emissions overall the product life cycle, the paper focuses on the manufacturing phase in terms of process planning. A carbon emission evaluation method for the manufacturing process plans has been proposed in this paper. In this method, the input and output models of unit process level are combined to form an entire input and output model for a manufacturing process plan and then quantifying the amount of carbon emissions from individual processes. This method can be used effectively to make decisions for manufacturers to pinpoint detailed breakdown of the emission factors and select the manufacturing process plan with least carbon emissions; meanwhile, it provides opportunities to improve the current process plan under a greater insight into carbon emission analysis in manufacturing phase of a product life cycle. In the future, the extension of the framework into available process technology, manufacturing equipment, and process parameter optimization models are worthy of future investigation, and new algorithms for modifying and replanning process plans should be developed to ensure the efficiency of this process.

\section{Conflict of Interests}

The authors declare that there is no conflict of interests regarding the publication of this paper.

\section{Acknowledgments}

The work described in this paper was supported by the National Natural Science Foundation of China (Grant no. 51275365) and the National 863 Program of China (Grant no. 2012AA040101-2). These financial contributions are gratefully acknowledged.

\section{References}

[1] K. Govindan, R. Khodaverdi, and A. Jafarian, "A fuzzy multi criteria approach for measuring sustainability performance of a supplier based on triple bottom line approach," Journal of Cleaner Production, vol. 47, pp. 345-354, 2013.

[2] M.-L. Tseng, A. S. F. Chiu, R. R. Tan, and A. B. SiribanManalang, "Sustainable consumption and production for Asia: sustainability through green design and practice," Journal of Cleaner Production, vol. 40, pp. 1-5, 2013.

[3] H. J. Cao, H. C. Li, H. Q. Cheng, Y. Luo, R. X. Yin, and Y. P. Chen, "A carbon efficiency approach for life-cycle carbon emission characteristics of machine tools," Journal of Cleaner Production, vol. 37, pp. 19-28, 2012.

[4] A. B. Culaba and M. R. I. Purvis, "A methodology for the life cycle and sustainability analysis of manufacturing processes," Journal of Cleaner Production, vol. 7, no. 6, pp. 435-445, 1999.

[5] K. Ramani, D. Ramanujan, W. Z. Bernstein et al., "Integrated sustainable life cycle design: a review," Journal of Mechanical Design, Transactions of the ASME, vol. 132, no. 9, Article ID 091004, 2010.

[6] J. Jeswiet and S. Kara, "Carbon emissions and CES in manufacturing," CIRP Annals-Manufacturing Technology, vol. 57, no. 1, pp. 17-20, 2008.

[7] J. R. Duflou, J. W. Sutherland, D. Dornfeld et al., "Towards energy and resource efficient manufacturing: a processes and systems approach," CIRP Annals-Manufacturing Technology, vol. 61, no. 2, pp. 587-609, 2012.

[8] N. Weinert, S. Chiotellis, and G. Seliger, "Methodology for planning and operating energy-efficient production systems," CIRP Annals: Manufacturing Technology, vol. 60, no. 1, pp. 4144, 2011.

[9] Y.-C. Choi and P. Xirouchakis, "A production planning in highly automated manufacturing system considering multiple process plans with different energy requirements," The International Journal of Advanced Manufacturing Technology, vol. 70, no. 5-8, pp. 853-867, 2014.

[10] K. Fang, N. Uhan, F. Zhao, and J. W. Sutherland, "A new approach to scheduling in manufacturing for power consumption and carbon footprint reduction," Journal of Manufacturing Systems, vol. 30, no. 4, pp. 234-240, 2011.

[11] A. Laurent, S. I. Olsen, and M. Z. Hauschild, "Carbon footprint as environmental performance indicator for the manufacturing industry," CIRP Annals-Manufacturing Technology, vol. 59, no. 1, pp. 37-40, 2010.

[12] C. Herrmann and S. Thiede, "Process chain simulation to foster energy efficiency in manufacturing," CIRP Journal of 
Manufacturing Science and Technology, vol. 1, no. 4, pp. 221-229, 2009.

[13] S. Rahimifard, Y. Seow, and T. Childs, "Minimising embodied product energy to support energy efficient manufacturing," CIRP Annals-Manufacturing Technology, vol. 59, no. 1, pp. 2528, 2010.

[14] H. C. Li, H. J. Cao, and X. Y. Pan, "A carbon emission analysis model for electronics manufacturing process based on valuestream mapping and sensitivity analysis," International Journal of Computer Integrated Manufacturing, vol. 25, no. 12, pp. 11021110, 2012.

[15] A. J. C. Trappey, C. V. Trappey, C.-T. Hsiao, J. J. R. Ou, and C.-T. Chang, "System dynamics modelling of product carbon footprint life cycles for collaborative green supply chains," International Journal of Computer Integrated Manufacturing, vol. 25, no. 10, pp. 934-945, 2012.

[16] C. B. Li, Y. Tang, L. G. Cui, and P. Y. Li, "A quantitative approach to analyze carbon emissions of CNC-based machining systems," Journal of Intelligent Manufacturing, 2013.

[17] S. Schrems, C. Eisele, and E. Abele, "Methodology for an energy and resource efficient process chain design," in Proceedings of the 18th CIRP International Conference on Life Cycle Engineering, pp. 299-304, May 2011.

[18] A. Fysikopoulos, K. Salonitis, and G. Chryssolouris, "Energy efficiency of laser based manufacturing processes," in Proceedings of the 28th International Congress on Applications of Lasers and Electro-Optics (ICALEO '09), pp. 1525-1531, Orlando, Fla, USA, November 2009.

[19] X. Shi and H. Meier, "Carbon emission assessment to support planning and operation of low-carbon production systems," in Proceedings of the 45th CIRP Conference on Manufacturing Systems, vol. 3, pp. 329-334, May 2012.

[20] A. C. K. Choi, H. Kaebernick, and W. H. Lai, "Manufacturing processes modelling for environmental impact assessment," Journal of Materials Processing Technology, vol. 70, no. 1-3, pp. 231-238, 1997.

[21] F. Zhao, V. R. Murray, K. Ramani, and J. W. Sutherland, “Toward the development of process plans with reduced environmental impacts," Frontiers of Mechanical Engineering, vol. 7, no. 3, pp. 231-246, 2012.

[22] S. Hu, F. Liu, Y. He, and T. Hu, "An on-line approach for energy efficiency monitoring of machine tools," Journal of Cleaner Production, vol. 27, pp. 133-140, 2012.

[23] Climate Change Department of National Development and Reform Commission, Announcement to Publish 2009 Baseline Emission Factors for Regional Power Grids in China, 2009. 


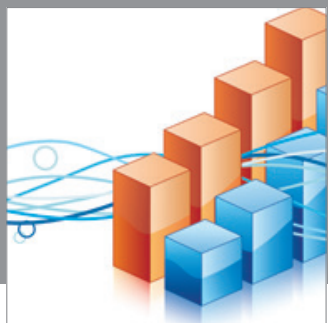

Advances in

Operations Research

mansans

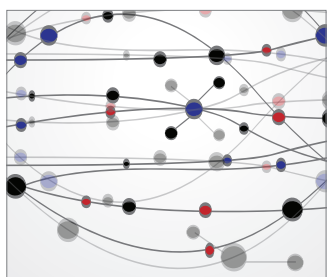

The Scientific World Journal
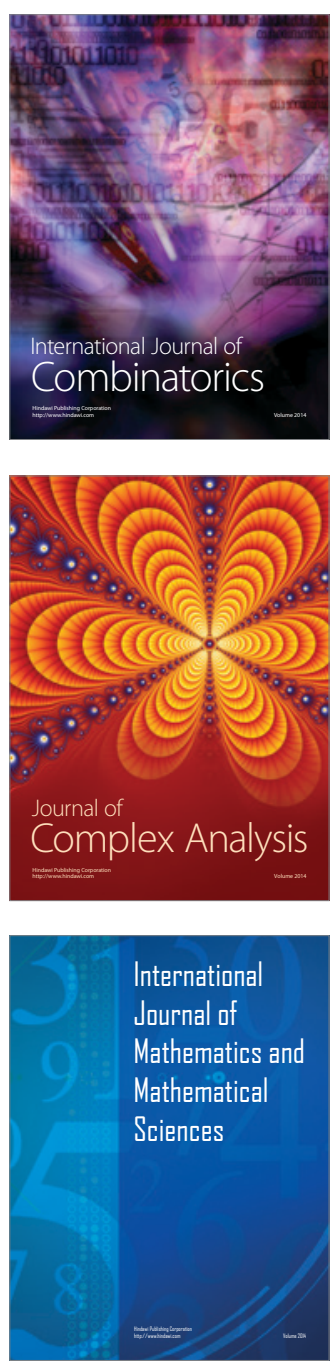
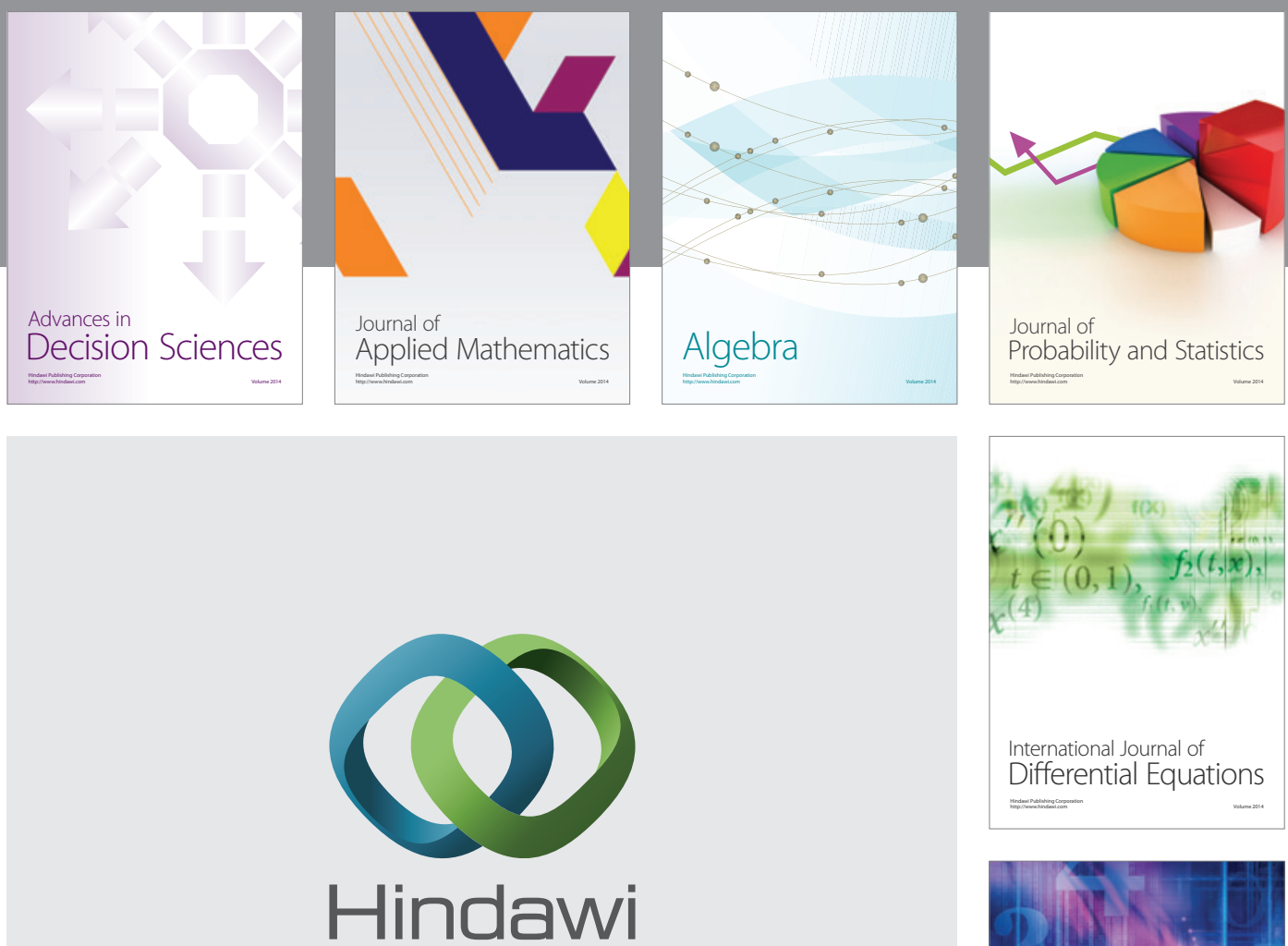

Submit your manuscripts at http://www.hindawi.com
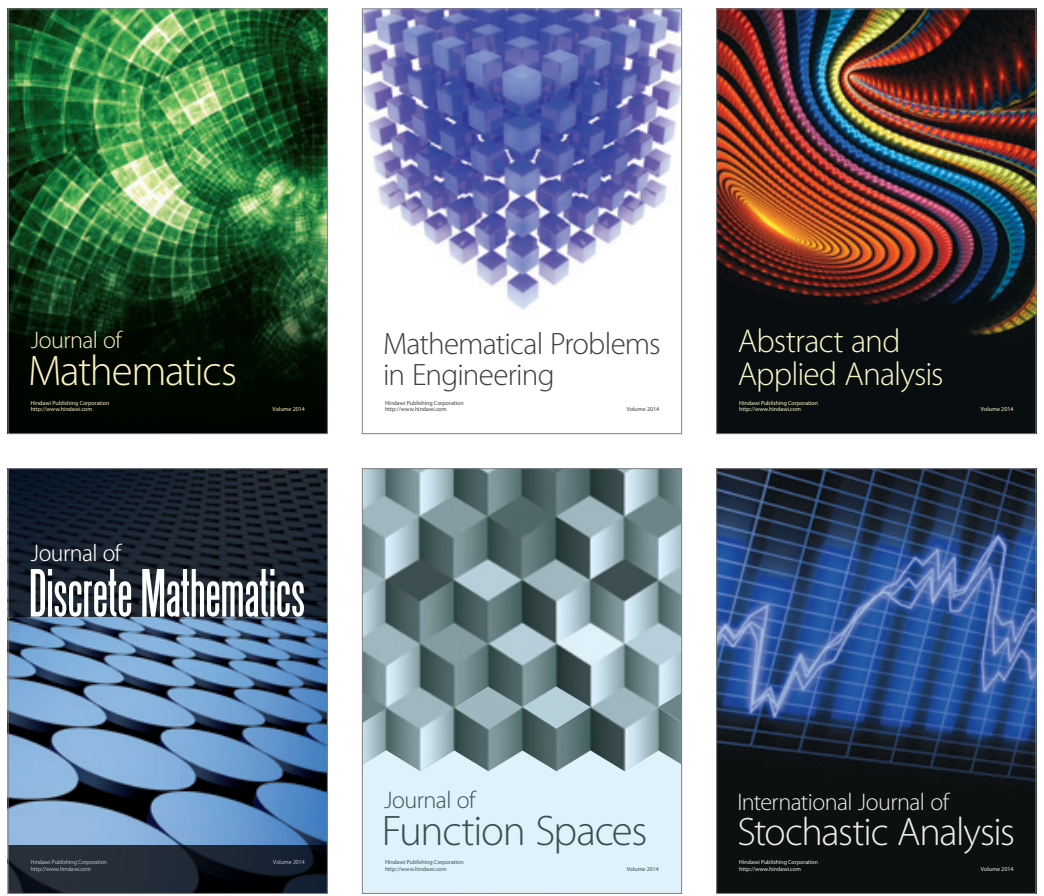

Journal of

Function Spaces

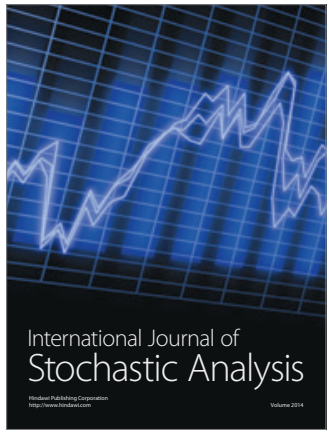

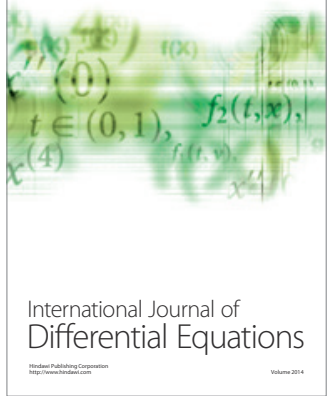
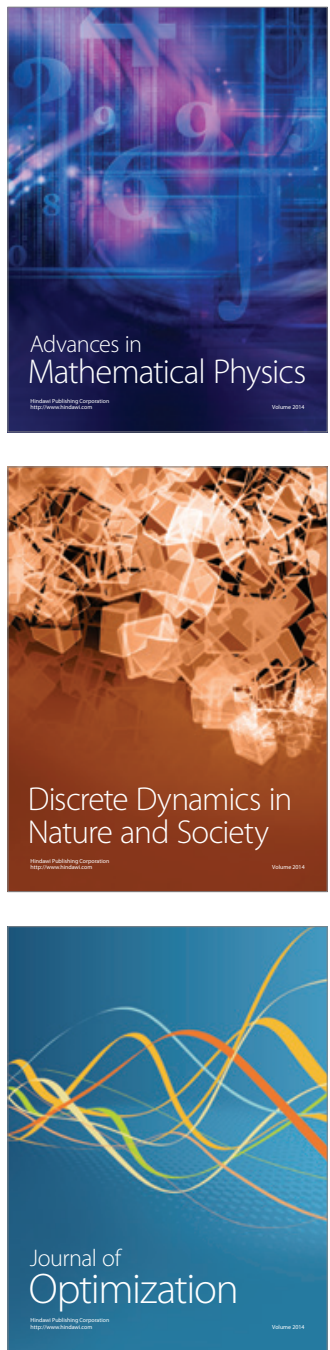